\title{
Multiple selective media for the isolation of anaerobic bacteria from clinical specimens
}

\author{
MWD WREN \\ From the Microbiology Department, North Middlesex Hospital, Edmonton, London N18 1QX, UK
}

SUMMARY Using fresh clinical material, a comparison of a number of anaerobic selective media was made. For Gram-negative anaerobes nalidixic acid tween agar (NAT), neomycin agar (NA), and neomycin-vancomycin agar (NVA) all performed equally well. Kanamycin-containing media were more inhibitory to all Gram-negative anaerobes other than Bacteroides fragilis and B. melaninogenicus. When the recovery of Gram-positive anaerobes was examined NAT performed better than any of the other selective media used. No single selective medium could recover all anaerobes. Better isolation was achieved using a combination of two selective media (the best combinations being NAT and NVA or NAT and NA). Only a combination of three selective media gave the maximum recovery of anaerobes in this study (NAT, NVA, and NA or KA).

The successful isolation of anaerobic bacteria from clinical material is dependent upon several factors, one of which is the provision of suitably enriched selective and non-selective media.

Selective media are necessary since many specimens, particularly those from the abdominal region, may also contain large numbers of Proteus species and other coliforms that outgrow anaerobes on nonselective media. Indeed, a blood agar plate may recover only about $60 \%$ of the anaerobic flora present in such specimens, and recovery is sometimes difficult in the absence of a selective plate.

There are a number of selective media commonly used for the isolation of both Gram-positive and Gram-negative anaerobes. These media were compared to determine which types of media were best for each group of anaerobes. This paper also examines the performance of each medium singly and in combination with the other selective media to investigate which combination (or combinations), if any, provides the best cover for anaerobes of all types, thus ensuring maximum recovery of all genera.

\section{Material and methods}

\section{CULTURE TECHNIQUE}

Pus from the following cases was obtained: thoracic empyema (7), peritonitis (2), gastrectomy wound (2),

Received for publication 17 July 1979 and one case each of retrogastric cavity abscess, retroperitoneal abscess, abdominoperineal resection wound, subphrenic abscess, ischiorectal abscess, ovarian abscess, endometritis, osteomyelitis, abdominal wall abscess, and perianal abscess.

Pus was collected directly into sterile universal bottles and delivered directly to the laboratory for immediate microbiological investigation.

A direct smear was made and examined after Gram staining, and the numbers and types of bacteria present in the specimen were recorded. A large loopful of pus was plated onto Columbia blood agar and MacConkey agar (both from Lab M, Salford, Lancs) for incubation in an atmosphere of air plus $10 \%$ carbon dioxide at $37^{\circ} \mathrm{C}$. These plates were examined after overnight incubation, reincubated, and read again after 48 hours. For anaerobic incubation a large loopful of pus was plated onto freshly poured plates of brucella blood agar, nalidixic acid-tween-agar (NAT), neomycin agar (NA), neomycin-vancomycin agar (NVA), kanamycin agar (KA), kanamycin-vancomycin agar (KVA), and rifampicin agar (RA).

All anaerobic media were incubated in stainless steel anaerobic jars fitted with a modified catalyst sachet (Baldwin, 1975) and set up in the manner recommended by Watt et al. (1976). A gas mixture of $90 \%$ hydrogen and $10 \%$ carbon dioxide was used. All jars were incubated for 48 hours at $37^{\circ} \mathrm{C}$ before the initial examination and then reincubated until the fifth day and read again. 
Direct examination of pus for short chain fatty acids by gas-liquid chromatography as a presumptive diagnosis of anaerobic involvement was made.

MEDIA PREPARATION

Brucella agar (Difco Laboratories) was reconstituted, bottled, and sterilised at $121^{\circ} \mathrm{C}$ for 15 minutes. Bottles of brucella agar were then melted when required and the following supplements were added:

Oxalated horse blood (Oxoid Ltd) $5 \%$

Haemin (BDH Ltd)

Vitamin K3 (Sigma Ltd) $0.005 \mathrm{~g} / 1$ $0.0005 \mathrm{~g} / \mathrm{l}$.

This constituted the basal medium and was used as the anaerobic blood agar plate. The various selective media were made by adding the following antibiotics: Neomycin agar $\quad 0.075 \mathrm{~g} / 1$ neomycin Neomycin-vancomycin agar $\quad 0.075 \mathrm{~g} / \mathrm{l}$ neomycin $0.0075 \mathrm{~g} / \mathrm{l}$ vancomycin Kanamycin agar $\quad 0.075 \mathrm{~g} / \mathrm{l}$ kanamycin Kanamycin-vancomycin agar 0.075 g/1 kanamycin $0.0075 \mathrm{~g} / \mathrm{l}$ vancomycin

Rifampicin agar $0.05 \mathrm{~g} / \mathrm{l}$ rifampicin

Nalidixic acid-tween agar was prepared according to the method previously published (Wren, 1978). All anaerobic plates were freshly prepared and used on the day of pouring.

IDENTIFICATION OF AEROBIC BACTERIA All aerobic and facultatively anaerobic bacteria were identified using the criteria laid down by Cowan (1974).
IDENTIFICATION OF ANAEROBIC BACTERIA All anaerobic isolates were identified by biochemical criteria (Holdeman and Moore, 1977) and by gasliquid chromatography.

\section{Results}

GRAM-NEGATIVE ANAEROBES (Table 1)

A total of 39 anaerobic Gram-negative bacteria were recovered made up of 29 bacteroides, 8 fusobacteria, and two veillonellae. Blood agar managed to recover only $79.4 \%$ of strains, the remainder being overgrown by facultative bacteria and by rapidly growing strains of Bacteroides fragilis and Fusobacterium nucleatum. NAT, NA, and NVA all recovered well in excess of this figure, NAT recovering $94.8 \%$ of the total strains and both NA and NVA recovering $92.3 \%$. The two strains not recovered by NAT were a strain of $B$. praeacutus isolated only on NVA and a strain of $B$. disiens recovered by both NA and NVA. Kanamycincontaining media recovered $B$. fragilis and $B$. melaninogenicus with a frequency equal to that of NAT and neomycin-containing media but behaved poorly in the isolation of other types of bacteroides. Furthermore, kanamycin media were completely inhibitory to fusobacteria whereas NAT, NA, and NVA readily grew organisms of this genus. Rifampicin agar (RA) grew only one organism, $F$. mortiferum, an organism known to be resistant to this antibiotic.

Veillonellae also failed to grow on kanamycincontaining media and on NVA although no

Table 1 Recovery of Gram-negative anaerobes

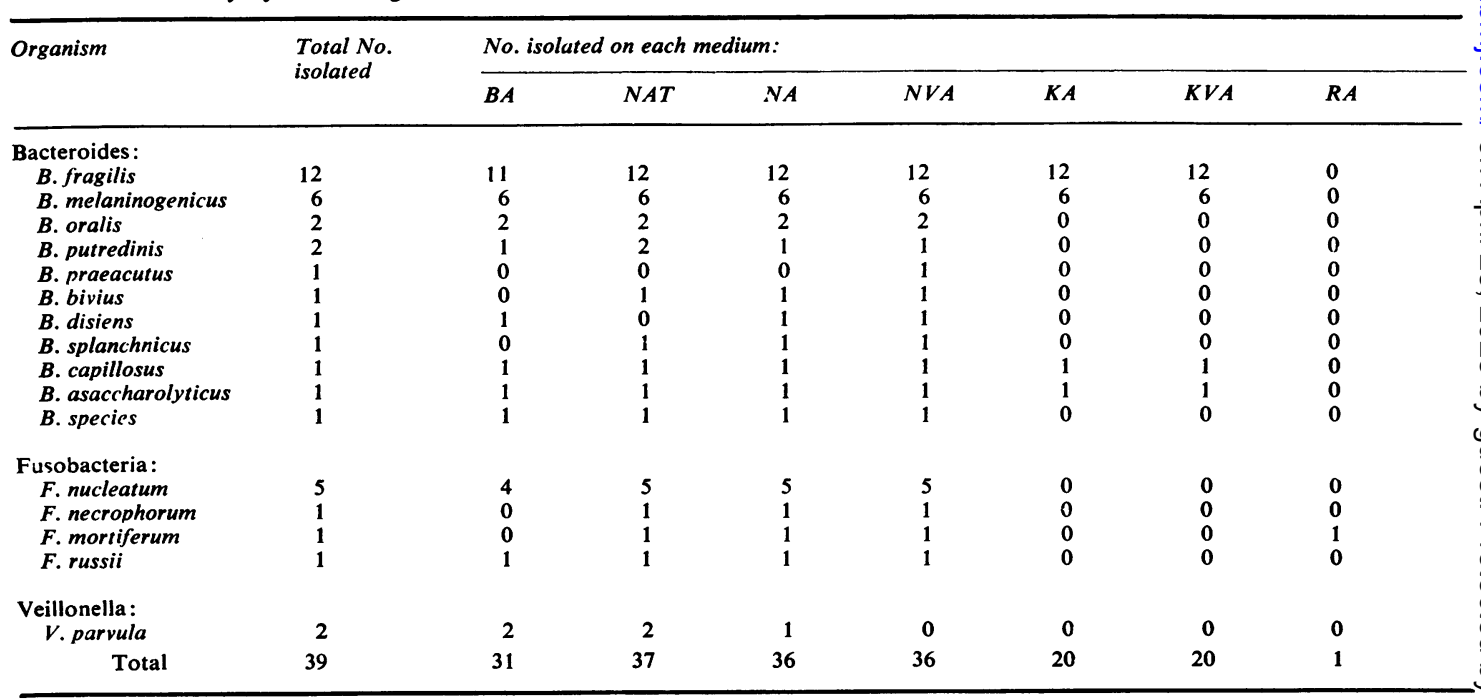


explanation can be given for the failure of the NVA plates. Only one of the two veillonellae was recovered by NA, but both grew on NAT.

Within this group of organisms NAT behaved marginally better than the other selective media, but only a combination of NAT and NVA achieved maximum recovery of Gram-negative anaerobes.

GRAM-POSITIVE ANAEROBES (Table 2)

A total of 33 Gram-positive anaerobes were recovered. Of these strains, 15 were peptococci, 10 were peptostreptococci, two were clostridia, and six were non-sporing Gram-positive rods (five Eubacterium species and one propionibacterium). Blood agar recovered only $60.6 \%$ of strains and behaved more poorly with Gram-positive anaerobes than with Gram-negative forms. NAT was the only medium to recover more than $90 \%(93.9 \%)$ of strains. Neomycin agar recovered only $51.5 \%$ and kanamycin agar could recover only $29 \cdot 2 \%$ of strains. Media containing vancomycin failed to recover any Gram-positive organism, as was expected. NAT failed to recover a peptococcus isolated only on NA and a clostridium which was recovered on both NA and KA. Taking both groups of anaerobes overall, the isolation rates ranged from $27.7 \%$ (KVA) to $94.4 \%$ (NAT), RA recovering only $1.4 \%$. Combinations of selective media in pairs achieved isolation rates of between $29.2 \%$ and $98.6 \%$, depending upon the combination used.

It is clear that a combination of selective media gives better results than a single medium, the best combination appearing to be either NAT with NA or NAT with NVA. However, a combination of three media (NAT, NVA, and NA or KA) was the only way to achieve maximum recovery.

Such combinations of selective media are necessary since a number of strains (18 of 72 in this study) will be recovered on only one of the media employed. In this study 16 strains (14 Grampositive and two Gram-negative) were recovered only on NAT, one strain (Gram-negative) on NVA, and one (Gram-positive) on NA.

\section{Discussion}

The need for a selective medium in the primary plating regime when searching for anaerobic bacteria in clinical material is well recognised (Dowell, 1974; Martin, 1974; Killgore et al., 1973; Sutter et al., 1975; Wren et al., 1977; Wren, 1978). It is also known that all selective media are, to some degree, inhibitory to the organisms for which they were designed, and previous work has shown that neomycin is less inhibitory than kanamycin for $F$. nucleatum, anaerobic cocci, and bifidobacteria (Finegold, 1970). While the results of the present study supported this earlier contention the statement that these two antibiotics are of similar selectivity for other fusobacteria cannot be supported.

The results of the present study indicate that the use of a single selective medium randomly chosen may lead the microbiologist into a false belief that most types, if not all, of anaerobe will be recovered. The use of a single selective plate together with blood agar may result in the recovery of $72 \%$ to $96 \%$ of

Table 2 Recovery of Gram-positive anaerobes

\begin{tabular}{|c|c|c|c|c|c|c|c|c|}
\hline \multirow[t]{2}{*}{ Organism } & \multirow{2}{*}{$\begin{array}{l}\text { Total No. } \\
\text { isolated }\end{array}$} & \multicolumn{7}{|c|}{ No. isolated on each medium: } \\
\hline & & $B A$ & $N A T$ & $N A$ & $N V A$ & $K A$ & $K V A$ & $R A$ \\
\hline $\begin{array}{l}\text { Peptococcus: } \\
\text { Pc. magnus } \\
\text { Pc. prevotii } \\
\text { Pc. asaccharolyticus } \\
\text { Pc. species }\end{array}$ & $\begin{array}{l}5 \\
6 \\
3 \\
1\end{array}$ & $\begin{array}{l}3 \\
3 \\
2 \\
0\end{array}$ & $\begin{array}{l}5 \\
6 \\
3 \\
0\end{array}$ & $\begin{array}{l}3 \\
4 \\
2 \\
1\end{array}$ & $\begin{array}{l}\mathbf{0} \\
\mathbf{0} \\
\mathbf{0} \\
\mathbf{0}\end{array}$ & $\begin{array}{l}2 \\
3 \\
0 \\
0\end{array}$ & $\begin{array}{l}\mathbf{0} \\
\mathbf{0} \\
\mathbf{0} \\
\mathbf{0}\end{array}$ & $\begin{array}{l}\mathbf{0} \\
\mathbf{0} \\
\mathbf{0} \\
\mathbf{0}\end{array}$ \\
\hline $\begin{array}{l}\text { Peptostreptococcus: } \\
\text { Pst. anaerobius } \\
\text { Pst. productus } \\
\text { Pst. micros }\end{array}$ & $\begin{array}{l}6 \\
2 \\
2\end{array}$ & $\begin{array}{l}4 \\
2 \\
1\end{array}$ & $\begin{array}{l}6 \\
2 \\
2\end{array}$ & $\begin{array}{l}1 \\
1 \\
1\end{array}$ & $\begin{array}{l}\mathbf{0} \\
\mathbf{0} \\
\mathbf{0}\end{array}$ & $\begin{array}{l}1 \\
0 \\
0\end{array}$ & $\begin{array}{l}\mathbf{0} \\
\mathbf{0} \\
\mathbf{0}\end{array}$ & $\begin{array}{l}\mathbf{0} \\
\mathbf{0} \\
\mathbf{0}\end{array}$ \\
\hline $\begin{array}{l}\text { Clostridium: } \\
\text { Cl. septicum } \\
\text { Cl. species }\end{array}$ & $\begin{array}{l}1 \\
1\end{array}$ & $\begin{array}{l}1 \\
1\end{array}$ & $\begin{array}{l}1 \\
0\end{array}$ & $\begin{array}{l}1 \\
1\end{array}$ & $\begin{array}{l}\mathbf{0} \\
\mathbf{0}\end{array}$ & $\begin{array}{l}1 \\
1\end{array}$ & $\begin{array}{l}0 \\
0\end{array}$ & $\begin{array}{l}\mathbf{0} \\
\mathbf{0}\end{array}$ \\
\hline $\begin{array}{l}\text { Eubacterium: } \\
\text { Eu. lentum } \\
\text { Eu. combessii }\end{array}$ & $\begin{array}{l}4 \\
1\end{array}$ & $\begin{array}{l}3 \\
0\end{array}$ & $\begin{array}{l}4 \\
1\end{array}$ & $\begin{array}{l}1 \\
0\end{array}$ & $\begin{array}{l}\mathbf{0} \\
\mathbf{0}\end{array}$ & $\begin{array}{l}\mathbf{0} \\
\mathbf{0}\end{array}$ & $\begin{array}{l}0 \\
0\end{array}$ & $\begin{array}{l}\mathbf{0} \\
\mathbf{0}\end{array}$ \\
\hline $\begin{array}{l}\text { Propionibacterium: } \\
\text { Pr. acnes } \\
\text { Total }\end{array}$ & $\begin{array}{r}1 \\
33\end{array}$ & $\begin{array}{r}1 \\
21\end{array}$ & $\begin{array}{r}1 \\
31\end{array}$ & $\begin{array}{c}1 \\
17\end{array}$ & $\begin{array}{l}\mathbf{0} \\
\mathbf{0}\end{array}$ & $\begin{array}{l}1 \\
9\end{array}$ & $\begin{array}{l}0 \\
0\end{array}$ & $\begin{array}{l}0 \\
0\end{array}$ \\
\hline
\end{tabular}


the total number of anaerobes in a group of specimens. However, in the presence of a swarming Proteus species, a large number of coliforms, or faecal streptococci, the recovery rate for anaerobes may fall to as little as $27 \%$. It is important, therefore, that the choice of selective media be carefully made.

This study reveals that certain selective media are more efficient in the isolation of anaerobes than are others and that a combination of at least two selective plates is to be preferred to achieve near maximal recovery.

The findings also indicate that such combinations of media must be made with media that complement each other in the regimen, that is to say, that they provide for maximal recovery of both Gramnegative and Gram-positive anaerobes. Even a combination of two media may fail to recover all the anaerobes present in a specimen.

For the recovery of Gram-positive anaerobes NAT stood out from the rest, achieving better recovery of this group of anaerobes than any other medium in this study. I have already demonstrated the superiority of this medium to kanamycin agar (Wren, 1978). NAT, however, failed to recover clostridia that are isolated by NA and KA. The inhibitory nature of $\mathrm{KA}$, even for many non-sporing anaerobes, makes this medium particularly useful for the recovery of clostridia (Wren, unpublished data).

The superior recovery of NAT for Gram-positives could be explained by sampling error, which tends to occur to a greater extent with Gram-positives due to clumping within the pus (Bartlett et al., 1976). Another explanation is that the aminoglycoside antibiotics are particularly inhibitory to this group of anaerobes at the concentrations used in selective media, especially the anaerobic cocci of which 12 strains failed to grow on NA and 19 failed to grow on KA. If this inhibitory nature is confirmed then nalidixic acid provides a superior alternative for the recovery of this group, which accounts for $34 \%$ of isolates in clinical material, clearly an important group.

For the isolation of Gram-negative anaerobes it appears that the choice should be made from NAT, NVA, and NA, these three behaving with almost equal frequency although NVA does have the advantage of removing Gram-positive flora which may make isolation of Gram-negatives more difficult in a mixed infection. Many slowly growing Gram-negative anaerobes can be overgrown by Gram-positive cocci. The failure of the NVA plates to recover the two veillonellae, however, has no explanation.

Medium containing kanamycin cannot be recommended as a general selective medium for the
Gram-negative group since although the recovery of $B$. fragilis and $B$. melaninogenicus was efficient this medium fails to recover many other bacteroides and all fusobacteria. As a result, the use of a kanamycinvancomycin-laked blood agar plate as the only selective plate in the primary plating regime (as used in some laboratories) should be discouraged. Similarly, rifampicin agar has no place in the clinical situation since only $F$. mortiferum, $F$. varium, and a few clostridia possess the ability to grow on this medium, although this may be of use in normal flora studies.

In conclusion, the choice of selective media for anaerobes in the clinical situation seems to be from NAT, NVA, and NA, with the added benefits of KA for the recovery of the clostridia. In this study only a combination of three selective media (NAT, NVA, and either NA or KA) achieved the maximum recovery of anaerobes. However, the involvement of three selective media in the primary plating regimen may be economically undesirable but the use of two selective media, one used for Gram-negatives and one for Gram-positives, should be strongly considered.

\section{References}

Baldwin, A. W. F. (1975). An improved catalyst sachet for anaerobic jars. Medical Laboratory Technology, 32, 329-330.

Bartlett, J. G., Sullivan-Sigler, N., Louie, T. J., and Gorbach, S. L. (1976). Anaerobes survive in clinical specimens despite delayed processing. Journal of Clinical Microbiology, 3, 133-136.

Cowan, S. T. (1974). Cowan and Steel's Manual for the Identification of Medical Bacteria, 2nd edition. Cambridge University Press, London.

Dowell, V. R., Jr. (1974). Collection of clinical specimens and primary isolation of anaerobic bacteria. In Anaerobic Bacteria: Role in Disease, edited by A. Balows, V. R. Dowell, Jr., R. M. DeHaan, and L. B. Guze, pp. 9-16. Thomas, Springfield, Illinois.

Finegold, S. M. (1970). Isolation of anaerobic bacteria. In Manual of Clinical Microbiology, edited by J. E. Blair, E. H. Lennette, and J. P. Truant, pp. 265-279. American Society for Microbiology, Bethesda, Maryland.

Holdeman, L. V., and Moore, W. E. C. (1977). Anaerobe Laboratory Manual, 4th edition. Virginia Polytechnic Institute and State University, Blacksburg, Virginia.

Killgore, G. E., Starr, S. E., Del Bene, V. E., Whaley, D. N., and Dowell, V. R., Jr. (1973). Comparison of three anaerobic systems for the isolation of anaerobic bacteria from clinical specimens. American Journal of Clinical Pathology, 59, 552-559.

Martin, W. J. (1974). Isolation and identification of anaerobic bacteria in the clinical laboratory. A two year experience. Mayo Clinic Proceedings, 49, 300-308. 
Sutter, V. L., Vargo, V., and Finegold, S. M. (1975). Wadsworth Anaerobic Bacteriology Manual, 2nd edition. Dept. of Continuing Education in Health Sciences, University of California Extension, Los Angeles.

Watt, B., Collee, J. G., and Brown, R. (1976). Tests of performance of anaerobic jars. Journal of Clinical Pathology, 29, 534-536.

Wren, M. W. D. (1978). A new selective medium for the isolation of non-sporing anaerobic bacteria from clinical specimens. Medical Laboratory Sciences, 35,
371-378.

Wren, M. W. D., Baldwin, A. W. F., Eldon, C. P., and Sanderson, P. J. (1977). The anaerobic culture of clinical specimens: a 14-month study. Journal of Medical Microbiology, 10, 49-61.

Requests for reprints to: MWD Wren, Microbiology Department, North Middlesex Hospital, Edmonton, London N18 1QX, UK. 